\title{
ReSEarch Article \\ Varietal performance of rice under different source of nutrition in high altitude and tribal areas of Andhra Pradesh
}

\author{
A. Upendra Rao, K. Tejeswara Rao, D. Sekhar, V. Visa Lakshmi and N. Hari Satyanarayana
}

\begin{abstract}
SUMMARY
A field experiment was conducted for two consecutive Kharif seasons of 2012-13 and 2013-14 in a Split Plot Design with three replications, at Agricultural Research Station, Seethampeta, Andhra Prtadesh, India to generate scientific data on organic farming, integrated nutrient and pest management practices, chemical farming with four prominent varieties of rice viz., MTU 1001, RGL 2538, BPT 5204 and MTU 7029 in high altitude and tribal areas of Andhra Pradesh. Results showed that, grain yield of rice was reduced in organic farming by 37 per cent and 30.23 per cent compared to chemical farming and INM practices. Growth, yield attributes of rice also reduced noticeably in organic farming. Whereas, organic farming recorded higher root biomass per hill at flowering, higher post nutrient status of available nitrogen, phosphorus and potassium and lesser incidence of diseases and pests over INM and chemical farming. Chemical farming recorded higher growth, yield attributes, yield and returns. Among the cultivars, MTU 1001 showed better performance and recorded the higher grain yield and straw yields and least affected by diseases and pests compared to other varieties.
\end{abstract}

Key Words : Rice, Organic farming, INM, Chemical farming, Varieties

How to cite this article : Upendra Rao, A., Tejeswara Rao, K., Sekhar, D., Visa Lakshmi V. and Hari Satyanarayana, N. (2021). Varietal performance of rice under different source of nutrition in high altitude and tribal areas of Andhra Pradesh. Internat. J. Plant Sci., 16 (1): 46-51, DOI: 10.15740/HAS/IJPS/16.1/46-51, Copyright@ 2021: Hind Agri-Horticultural Society.

Article chronicle : Received : 17.10.2020; Revised : 11.11.2020; Accepted : 12.12.2020

MEMBERS OF THE RESEARCH FORUM

Author to be contacted :

K. Tejeswara Rao, Agricultural Research Station (ANGRAU), Seethampeta (A.P.) India

Email : tejaseniorscientist@gmail.com

Address of the Co-authors:

A. Upendra Rao, V. Visa Lakshmi and N. Hari Satyanarayana, Agricultural Research Station (ANGRAU), Seethampeta (A.P.) India

D. Sekhar, Department of Agronomy, Regional Agricultural Research

Station, Chintapalle, Visakhapatnam (A.P.)

(Email: sekhardesagiri@gmail.com 